\title{
ПОДХОД К ОЦЕНКЕ ИННОВАЦИОННОГО И РОЛЕВОГО ПОВЕДЕНИЯ УЧАСТНИКОВ ПРОЕКТНОЙ КОМАНДЫ
}

Авдеева А.П.(Московский государственный технический университет им.

Н.Э. Баумана, Москва, Россия), ap.avdeeva@rambler.ru Акопян Л.С. (Самарский государственный социально-педагогический

университет, Самара, Россия), akolubov@mail.ru

Ермолаева М.В., Кокуева Ж.М. (Московский государственный технический университет им. Н.Э. Баумана, Москва, Россия), mar-erm@mail.ru, kokueva@bmstu.ru

Лубовский Д.В. (Московский государственный психолого-педагогический университет, Москва, Россия), lubovsky@yandex.ru

乙tipluјugर्ume uर्u. 31.07.2021

9pmpunuर्जuध mर्णu. 09.08.2021

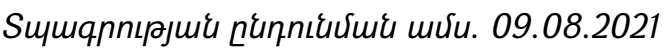

Исследована связь составляющих инновационного потенциала (готовность к инновациям, готовность к работе в команде, опыт работы в команде проекта) с помощью специально разработанных опросника ролевого поведения в команде и методики изучения типов инновационного поведения. Исследование с участием сотрудников промышленных предприятий в возрасте от 19 до 40 лет и стажем работы от 6 месяцев до 22 лет, задействованных в инновационных проектах, а также среди студентов технического вуза, показало, что наиболее предпочитаемым типом инновационного потенциала у работников со стажем является тип «модератор», а студенты чаще выбирают тип «ищущий возможности». Рассмотрены сходство и различия обоих типов. Показано, что студенты, по сравнению с работниками предприятий, переоценивают свою склонность к внедрению радикальных инноваций и, в целом, собственную решительность в профессиональной деятельности.

Ключевые слова: инновационный потенциал, ролевое поведение, инновационное поведение, проектная команда, типы инновационного потенциала.

DOI: https://doi.org/10.46991/SBMP/2021.4.2.065

Введение. В современной проектной деятельности особенно высоки требования к готовности проектной команды к инновациям, что предполагает управление социально-психологическими фракторами, которые стимулируют инновационную деятельность, овладение инновационным поведением, а также подразумевают целый ряд качеств субъекта инновационной деятельности [2]. 
Для обозначения готовности к инновациям используют термин «инновационный потенциал», который обозначает готовность к инновационной деятельности, внутренние ресурсы осмысленного и дифференцированного восприятия нововведений, а также адаптации к ним [3].

Современные модели инновационного потенциала выделяют в его структуре интеллектуальную (креативность, гибкость), мотивационно-волевую (мотивацию достижения успеха, интернальный локус контроля, инициативность, оптимизм) и социально-психологическую (тип ролевого поведения, толерантность к неопределенности, направленность на экспериментирование, склонность к риску) составляющие [1; 4; 5; 7]. Важно отметить, что одни и те же компетенции, такие как профессиональные знания, опыт, коммуникативная компетентность, а также творческие и мотивационные ресурсы составляют основу инновационных потенциалов и отдельной личности, и группы [7]. Необходимы разработка методов психологической оценки инновационного потенциала как интегральной характеристики субъекта профессиональной деятельности и исследование взаимосвязи его базовых составляющих и проявления его специфики в проектной командной деятельности.

Цель исследования заключалась в изучении взаимосвязи составляющих инновационного потенциала - готовности к инновациям, готовности к командообразованию и профессионального опыта работы в проектной команде.

Задачи исследования: разработка и апробация методики изучения составляющих инновационного потенциала; исследование взаимосвязи готовности к инновациям, готовности к командообразованию и профессионального опыта работы в команде проекта.

Методы. Исследование было проведено в два этапа. На первом этапе исследовалась взаимосвязь готовности к инновационной проектной деятельности и предпочитаемыми ролями в команде проекта как составляющих инновационного потенциала. На втором этапе исследована оценка влияния опыта работы в команде и личных предпочтений на структуру инновационного потенциала. Первый этап исследования проводился с группой сотрудников промышленных предприятий в возрасте от 19 до 40 лет и стажем работы от 6 месяцев до 22 лет, задействованных в инновационных проектах по осуществлению исследований, разработок и их внедрению в области машиностроения и других отраслей промышленности, например, в проекте по разработке и внедрению системы управления информацией на промышленном предприятии. В исследовании приняли участие 45 человек: 12 мужчин и 33 женщины. Средний возраст участников исследования - 25 лет 7 месяцев, средний трудовой стаж - 5,18 лет.

Во втором этапе исследования принимали участие студенты старших курсов экономических фракультетов технических вузов (бакалавриат, 
направление подготовки «Инноватика», $n=20)$, не имеющие значительного стажа и опыта работы в команде инновационного проекта, а также работающие менеджеры со стажем (n=30). Исследование осуществлялось с помощью тех же методик, что и на первом этапе. В исследовании были использованы 1) опросник ролевого поведения в команде М.В. Ермолаевой и Д.В. Лубовского, составленный на основе описания ролей, выделенных Р.М. Белбином и 2) методика изучения типов инновационного поведения (М.В. Ермолаева, Д.В. Лубовский).

Опросник ролевого поведения в команде состоит из 28 пунктов, в каждом из которых респонденту необходимо выбрать из двух описаний ролевого поведения одно как более характерное для него. Методика направлена на выявление восьми ролей в команде: мыслитель, искатель, координатор, конфригуратор, контролер, коллективист (душа команды), исполнитель, доводчик.

Для роли мыслителя характерно творческое мышление и способность решать сложные задачи, но, при этом, занятость творчеством и игнорирование второстепенных деталей. Искателю свойственны активность, открытость и общительность, хотя в силу излишнего оптимизма он может быстро потерять интерес. Роль координатора заключается в интеграции усилий коллег, уверенном руководстве принятием решений, умелом распределении полномочий.

Роль конфигуратора состоит в побуждении к действию, активности и настойчивости, хотя и не исключены конфликты с менее инициативными участниками команды. Для роли контролера-наблюдателя типичны рассудительность, проницательность и склонность к стратегическому мышлению, взвешенный анализ проблемы, но он сам не очень энергичен. Роль коллективиста подразумевает качества, незаменимые в командной работе (дипломатичность, гибкость, умение слушать, слышать и находить общий язык), но при этом нерешительность в критических ситуациях. Исполнитель отличается эфрфективностью и надежностью, но, в то же время, приверженностью традиции и некоторой негибкостью. Доводчик выполняет работу своевременно и качественно, успешно находит ошибки, допущенные другими, исправляет их, но тревожен и неохотно делится полномочиями с другими. Роль специалиста, т.е. работника, обладающего редкими знаниями и навыками, не была включена в ролевой репертуар, поскольку не каждая проектная команда испытывает потребность в таких работниках.

В основу методики изучения типов инновационного поведения (М.В. Ермолаева, Д.В. Лубовский) было заложено представление о двух типах инноваций - радикальных и инкрементальных. Первые существенно меняют положение вещей; инкрементальные инновации представляют собой локальные изменения, усовершенствования, не ведущие к радикальным переменам. В 
соответствии с этой дихотомией были выделены восемь типов инновационного поведения [2].

1. Креативщик - радикальные инновации, генерация новой идеи.

2. Ищущий возможности - радикальные инновации, ориентированность на поиск новых возможностей и проблемных областей.

3. Противодействующий давлению - радикальные инновации, смягчение противодействия со стороны окружения, урегулирование взаимоотношений сторон при продвижении новой идеи.

4. Внедряющий инновацию - радикальные инновации, внедрение инновационного решения и его превращение в стандартный элемент производственного процесса.

5. Модератор - инкрементальные инновации, регулирование взаимоотношений в команде для выявления проблемных областей в общей деятельности.

6. Координатор - инкрементальные инновации, устранение разногласий в процессе внедрения инновации, создание рабочей среды, поддерживающей творческую активность сотрудников.

7. Протагонист - инкрементальные инновации, превращение новых идей в практические действия, дополнение существующих технологий, инноваций и моделей.

8. Модернизатор - инкрементальные инновации, совершенствование внедренного, одобрение и доработка новой идеи, отыскание ранее не задействованных ресурсов.

Методика также включает 28 пунктов, в каждом из которых респонденту необходимо выбрать из двух описаний инновационного поведения одно как более характерное для него.

Результаты первого этапа исследования: Результаты исследования обнаружили взаимосвязь предпочтений ролей в команде и типов инновационного поведения. В табл. 1 представлены наиболее примечательные сочетания типов инновационного поведения и ролевого поведения в группе.

Таблица 1.

Сочетания предпочтений ролевого и инновационного поведения

\begin{tabular}{|l|c|l|l|l|l|l|}
\hline \multirow{2}{*}{ Роли } & \multicolumn{5}{|c|}{ Типы инновационного поведения } \\
\cline { 2 - 7 } & Креативщик & $\begin{array}{l}\text { Противодейст } \\
\text { вующий } \\
\text { давлению }\end{array}$ & $\begin{array}{l}\text { Внедряющий } \\
\text { инновацию }\end{array}$ & Модератор & $\begin{array}{l}\text { Коорди- } \\
\text { натор }\end{array}$ & Модернизатор \\
\hline Искатель & 6 & 2 & 3 & 2 & 7 & 5 \\
\hline $\begin{array}{l}\text { Контролер- } \\
\text { наблюдатель }\end{array}$ & & & & & \\
\hline
\end{tabular}




\begin{tabular}{|l|l|l|l|l|l|l|}
\hline Коллективист & 2 & 3 & & & & 3 \\
\hline Исполнитель & & & & 2 & & \\
\hline «Доводчик» & & & & 12 & 9 & \\
\hline
\end{tabular}

Связь предпочитаемых групповых ролей и инновационного поведения значима $\left(X^{2}=34,971 ; p=0,001\right)$. Анализ наиболее часто встречающихся парных сочетаний ролевого поведения и типов ИП показал, что роль «доводчика», успешного в поисках и исправлениях ошибок, сочетается с типом «модератор», который сравнивает варианты, выносит взвешенные решения в ходе обсуждения новой идеи, и с типом «координатор», который устраняет разногласия в процессе внедрения инновации. Такое сочетание представляется закономерным, поскольку обусловленная ролью политика «сглаживания углов» проявляется в согласовании мнений относительно целесообразности внедрения новой идеи (в случае радикальных инноваций) и координации точек зрения при внедрении инкрементальных инноваций. Закономерны также сочетания роли «искателя" и нескольких вариантов инновационного поведения («креативщика», «координатора», «модернизатора»), поскольку в них имеются черты, комплементарные ролевой модели «искателя». Данный вывод можно отнести именно к оцениванию готовности к определенному типу инновационного поведения и к командной работе в определенной командной роли.

Результаты второго этапа исследования: В табл. 2 представлены результаты сравнительного анализа оценки инновационного поведения по опроснику работниками со стажем и студентами.

Таблица 2.

Результаты субъективной оценки инновационного поведения участниками проекта и студентами.

\begin{tabular}{|c|c|c|c|c|c|c|c|c|c|}
\hline \multirow[b]{2}{*}{ группа } & \multicolumn{8}{|c|}{ Тип инновационного поведения } & \multirow[b]{2}{*}{ Всег } \\
\hline & $\begin{array}{c}\text { Креатив- } \\
\text { щик }\end{array}$ & $\begin{array}{c}\text { Ищущий } \\
\text { Возмож- } \\
\text { ности }\end{array}$ & $\begin{array}{c}\text { Противо- } \\
\text { действ. } \\
\text { давлению }\end{array}$ & $\begin{array}{c}\text { Внедр. } \\
\text { Иннова- } \\
\text { цию }\end{array}$ & $\begin{array}{c}\text { Модера- } \\
\text { тор }\end{array}$ & $\begin{array}{c}\text { Коорди- } \\
\text { натор }\end{array}$ & $\begin{array}{c}\text { Протаго- } \\
\text { нист }\end{array}$ & $\begin{array}{c}\text { Модерни- } \\
\text { затор }\end{array}$ & \\
\hline Студенты & 2 & 6 & 2 & 2 & 2 & 4 & 0 & 2 & 0 \\
\hline Работающие & 5 & 2 & 4 & 0 & 8 & 4 & 2 & 4 & 0 \\
\hline
\end{tabular}

Статистический анализ $\left(X^{2}=11,389 ; p=0,1\right)$ не выявил значимых различий между работниками со стажем и студентами. Анализ частоты выборов показал, что наиболее предпочтительным типом ИП у работников со стажем является тип «модератор», который сравнивает варианты, выносит взвешенные решения в ходе обсуждения новой идеи. Студенты чаще выбирают тип «ищущий возможности», который характеризуется ориентированностью на обнаружение 
новой возможности и новой проблемной области; стремлением наладить контакты в плане продвижения новой идеи. Интересно, что тип «модератор» и тип «ищущий возможности» схожи по признаку внедрения новой идеи: оба отвечают за организацию деятельности команды в целом на пути к внедрению инновации, однако, первый тип ИП относится к инкрементальным инновациям, а второй - к радикальным. Вероятно, студенты из-за недостатка опыта работы, склонны переоценивать собственную возможности внедрению радикальных инноваций и собственную решительность в профессиональной деятельности. В то же время и работники со стажем, и студенты одинаково часто выбирают тип «координатор», характеризующийся стремлением устранить разногласия в процессе внедрения инновации, активно участвовать в создании такой рабочей среды, в которой осуществляется поддержка творческой инициативы. Сходство выборов типов инновационного поведения студентами и работниками со стажем является важным результатом, который подтверждает мнение зарубежных исследователей о том, что преобразование организацией своей деятельности в соответствии с происходящими изменениями и эффективные инвестиции в человеческий капитал предполагает, прежде всего, создание инновационного климата в команде и ориентацию всех членов команды на совместную инновационную деятельность [8; 9]. Вероятно, бакалавры, обучающиеся по направлению подготовки «Инноватика», это понимают и ощущают в себе готовность соответствовать современным требованиям.

Обсуждение результатов. Полученные данные представляют большой интерес для различных образовательных практик, таких, как повышение квалификации и переподготовка работающих менеджеров, а также обучение будущих менеджеров в высшем образовании, в том числе их подготовка к работе над инновационными проектами. Для этого на специально организованных занятиях, направленных на рефлексию сформированности профессиональных компетенций, необходимо обсуждать несоответствия между предпочитаемой ролью в команде и той, что выявлена при помощи опросника, а также несоответствия между типом инновационного поведения, выявленным при помощи опросника, и тем, который предпочитает студент. Такие обсуждения дают возможность сорормировать у обучающихся более реалистические представления о своих профессиональных компетенциях, предотвратить трудности, связанные с выявленным несоответствием, а также выявить зону ближайшего развития профессиональных компетенций менеджера.

\section{Выводы.}

1. Проведенное исследование позволило подтвердить гипотезу, согласно которой между составляющими инновационного потенциала, такими как 
готовность к инновациям, готовность к работе в команде и профессиональным опытом работы в команде проекта, имеется связь.

2. Анализ частоты выборов показал, что наиболее предпочтительным типом инновационного потенциала у работников со стажем является тип «модератор», а студенты чаще выбирают тип «ищущий возможности». Оба типа схожи по признаку внедрения новой идеи: оба типа отвечают за организацию деятельности команды в целом на пути к внедрению инновации, однако, первый тип инновационного потенциала относится к инкрементальным инновациям, а второй - к радикальным. Эти данные свидетельствуют о готовности студентов переоценивать свою склонность к внедрению радикальных инноваций и, в целом, собственную решительность в профессиональной деятельности.

3. Полученные данные имеют практическое значение, поскольку устойчивость команды проекта, слаженность её работы является одним из важных факторов, которые наряду с фракторами доступности ресурсов, эфффективности системы контроля и др., влияют на эффективность выполнения проекта [6]. Перспективами дальнейших исследований по данной теме является разработка методик, направленных на оценку широкого спектра составляющих инновационного потенциала проектной команды.

\section{Литература}

1. Батурин Н.А., Науменко А.С., Ким Т.Д. Многоуровневая модель инновационного потенциала профессионала и подходы к её операционализации // Вестник ЮУрГУ. Сер. Психология. 2010. Вып. 8. №4. С. 48-58.

2. Ермолаева М.В., Кокуева Ж.М., Лубовский Д.В., Третьякова В.А. Изучение соотношения типов инновационного поведения и ролей в проектной команде. // Актуальные проблемы психологического знания. 2020. № 1 - 2 (53). С.34-45.

3. Каминский Е.Г. Инновационный потенциал личности: теоретические основания и подходы к изучению // Международный журнал исследований культуры. 2014. № 4 (17). С. 72-80.

4. Кравченко С.И., Кладченко И.С. Исследования сущности инновационного потенциала // Научные труды ДонНТУ. Донецк. Серия «Экономика». 2004. Вып. 68. С. 88-96.

5. Михайлова О.Б. Структура инновационного потенциала личности // Вестник НГУ. Сер. Психология. 2012. Т. 6. Вып. 1. С. 26-31.

6. Сафонова Д.А., Степанова А.И., Третьякова В.А. Формирование команды проекта // Кадровый потенциал инновационного развития: Международная научно-практическая конференция (Москва, 5 июня 2020г.): материалы конференции/Министерство науки и высшего 
образования РФ, ФГБОУ ВО МГТУ им. Н.Э. Баумана. М.: Изд-во МГТУ им. Н.Э. Баумана, 2020. С. 169-174.

7. Ушаков Д.В., Карнышев А.Д. Компетенции, креативность и предприимчивость как основы инновационных потенциалов личности и группы. // Материалы X международной научно-практической конфреренции «Экономическая психология: актуальные исследования и инновационные тенденции». Иркутск, 2009. С. 378-393.

8. Janssen 0 . The Joint Impact of Perceived Influence and Supervisor Supportiveness on Employee Innovative Behaviour // Journal of Occupational and Organizational Psychology. 2005. Vol. 78. P. 573-579. DOI:10.1348/096317905X25823

9. Scott S.G., Bruce R.A. Determinants of innovative behavior: A path model of individual innovation in the workplace // Academy of Management Journal. 1994. Vol. 37. P. 580-607. DOI:10.2307/256701.

\section{RESEARCH OF THE INNOVATIVE POTENTIAL OF THE PROJECT TEAM}

Avdeeva A. P. (Bauman Moscow State Technical University, Moscow, Russia) Akopyan L.S. (Samara State University of Social Sciences and Education, Samara, Russia)

Ermolaeva M.V., Kokueva Zh.M. (Bauman Moscow State Technical University, Moscow, Russia) Lubovskiy D.V. (Moscow State University of Psychology and Education, Moscow, Russia)

The relationship between the components of innovation potential (readiness for innovation, readiness to work in a team, experience in working in a project team) is studied using a specially developed questionnaire of role behavior in a team and a methodology for studying types of innovative behavior. Employees of industrial enterprises aged 19 to 40 years and work experience from 6 months to 22 years involved in innovative projects, as well as among students of a technical university took part in the research. It was shown that the most preferred type of innovative potential among employees with experience is the "moderator" type, and students more often choose the "opportunity seeker" type. The similarities and differences of both types are considered. It was shown that students, in comparison with employees of enterprises, overestimate their propensity to introduce radical innovations and, in general, their own determination in professional activity.

Keywords: innovative potential, role behavior, innovative behavior, project team, types of innovative potential. 